\title{
Fluctuating Asymmetry, Developmental Noise and Developmental Stability: Future Prospects for the Population Developmental Biology Approach
}

\author{
Vladimir M. Zakharov ${ }^{1}$, Elena G. Shadrina ${ }^{2}$ (D) and Ilya E. Trofimov ${ }^{1, *}$ \\ 1 Koltzov Institute of Developmental Biology of the Russian Academy of Sciences, 26 Vavilov Street, \\ 119334 Moscow, Russia; zakharov@ecopolicy.ru \\ 2 Institute for Biological Problems of Cryolithozone SB RAS, Lenin av., 41, 677980 Yakutsk, Russia; \\ e-shadrina@yandex.ru \\ * Correspondence: trofimov@ecopolicy.ru
}

Received: 8 July 2020; Accepted: 16 August 2020; Published: 18 August 2020

\begin{abstract}
Developmental noise-which level may vary within a certain backlash allowed by natural selection-is a reflection of the state of a developing system or developmental stability. Phenotypic variations inside the genetically determined norm observed in case of fluctuating asymmetry provide a unique opportunity for evaluating this form of ontogenetic variability. Low levels of developmental noise for the biologic system under study is observed under certain conditions, while its increase acts as a measure of stress. The concordance of changes in developmental stability with changes in other parameters of developmental homeostasis indicates the significance of fluctuating asymmetry estimates. All this determines the future prospects of the study of fluctuating asymmetry not only for developmental biology, but also for population biology. The study of developmental stability may act as the basis of an approach of population developmental biology to assess the nature of the phenotypic diversity and the state of natural populations under various impacts and during evolutionary transformations.
\end{abstract}

Keywords: fluctuating asymmetry; developmental noise; developmental stability; canalization of development; homeorhesis; developmental biology; population biology

\section{Introduction}

Fluctuating asymmetry, as minor deviations from perfect symmetry, is usually referred to a developmental noise [1-4]. Against the background of the mainstream of modern research aimed at revealing the strict determination of biologic processes-and especially their molecular mechanisms - this form of ontogenetic variability commonly is not among the priority targets for a particular attention. At the same time, special studies indicate the interest of analyzing fluctuating asymmetry due to the special nature of this form of variability [5-9]. Further research in this direction is aimed at developing integrated approaches for a comprehensive assessment of different types of symmetry and possible deviations from it [10-13].

The purpose of this study is an attempt to assess the significance of fluctuating asymmetry, as a measure of ontogenetic noise, both for assessing homeorhesis in developmental biology-and for assessing the state of an organism in solving various problems in the field of population biology. Achievement of this goal assumes a sequential consideration of the entire necessary range of issues: what is fluctuating asymmetry and how to evaluate its value, what are the results of its study in laboratory experiments and in nature and what could be applicability of such an analysis in the fields of developmental biology and population biology. It seems also important to make a try to identify the main reasons for possible uncertainties that may appear in a process of fluctuating asymmetry analysis. 


\section{What is Fluctuating Asymmetry?}

The formation of ideas about the stability of development is primarily associated with the study of ontogenetic characteristics in the field of developmental biology.

Development homeostasis or homeorhesis - as the most general ontogenetic characteristic — can be evaluated by various morphologic and physiological indicators of an organism condition [2,5,14-16]. Population approach proves to be significant for such studies. It also opens up an opportunity for the widespread use of this ontogenetic characteristic in the field of population studies. This is especially true for such measures of developmental homeostasis as developmental noise, a reliable estimate of which, due to the stochastic nature of the phenomenon, can be obtained only at the level of the group of individuals. The population approach is also important for the study of community and ecosystem.

Within the framework of general developmental homeostasis, two main aspects can be distinguished: canalization and developmental stability. Canalization refers to the ability to maintain development along a specific path or channel. High canalization means an opportunity of development along a certain trajectory under changing conditions, while plasticity assumes an ability to change the path of development. The study of canalization and plasticity of development opens up an opportunity to reveal the mechanisms of morphogenesis and evolutionary transformations. An analysis of the stability of development is important to characterize the state of a developing organism. The stability of development is understood as the perfection of the ontogenetic process, an ability to form a phenotypic effect without disturbances and failures. If in the analysis of canalization, the stability of a trajectory or a development channel is estimated, while characterizing the stability of development the width of this flow is estimated $[1,2,17]$.

A developmental stability study involves the assessment of phenotypic variability-which cannot be directly related to genetic or environmental differences. It can be defined as a noise or ontogenetic variability of a process of phenotypic realization of the genotype [2,18-20]. Isolation of this variability against the background of other forms of phenotypic diversity is not an easy task. In its pure form, it can be observed only when working with genetically identical individuals, the development of which occurs under identical conditions. An operational approach to assess this form of variability is to study fluctuating asymmetries. The same phenotypic effect on the left and right sides, which is achieved during individual development, is probably one of the most impressive evidence of the precision of the phenotypic realization of the genotype. Any deviations from this state can be considered as a manifestation of a chance spontaneous ontogenetic variability [21], developmental noise, the level of which is a characteristic of the state of a developing system. Its assessment assumes the necessity to evaluate the differences in the phenotypic realization of characters on two sides of the body. The peculiarity of these differences lies in the fact that the morphologic structure under study turns out to be normally developed on both sides of the body, while even what is a genetically determined value of a trait and what can be considered as a deviation from this given norm remains uncertain. As a genetically determined reaction norm, one can consider a certain range of character values. At the same time, it is impossible to conclude that there are any disturbances, rather, we are talking about certain inaccuracies in the phenotypic realization of the genotype, indicating some imperfection of developmental processes.

The presence of such differences, apparently, indicates a certain backlash allowed by natural selection, and the level of this variability within the backlash reflects the state of the system. This determines an opportunity of detecting possible differences in developmental stability for different biologic systems under study. Each trait has its own tolerance, backlash, which corresponds to the necessary level of precision of its realization in ontogenesis. The maintenance of the precision for any process is rather "costly" and "cost-benefit" balance proves to be always a key issue. If the number of limbs in most animal species is usually a highly canalized trait, then the number of hairs or bristles on them varies quite widely. Here, a comparison with the car's steering system is possible, in the absence of a certain tolerance, backlash, driving becomes a daunting task, and the movement occurs along a very uneven trajectory. It is not easy for a driver and may lead to an inconvenient result. 
Noise does not exist without a developing system-no developing system exists without a certain level of noise. A strong system is characterized by minimal noise. Noise is a characteristic of the system, and is a reflection of its developmental instability. A comparison with the author's work while typing is appropriate here. Typos do not exist without an operator; they are a characteristic of his/her work. Typos are inevitable, but their level can be minimized. The level of typos depends on both the state of the operator and the conditions under which he works. In theory, it may be possible to make a try to distinguish developmental noise and developmental stability [22-25], while in practice we anyhow can just to assess the actual level of developmental noise through fluctuating asymmetry estimates as a reflection of a state of developing system under the certain environmental conditions. At the same time, the use of phenodeviants (disturbances per se, developmental anomalies) [26,27] as an operational indicator of developmental stability in many cases is difficult. Studies of the impact of different environmental factors on various objects indicate that significant developmental disruptions may not occur with all the range of conditions suitable for development. The normal development of an organism along a certain trajectory is usually ensured in the whole range of conditions suitable for its life, which is an evidence of the canalization of development. At the same time, they can occur with a rather high frequency due to inbreeding or with a certain contamination $[19,28]$, acting as an indicator of specific effects.

\section{How to Assess Fluctuating Asymmetry}

Characterization of developmental stability is possible by assessing the level of developmental noise. In practice, possible approaches to solving the problem may be to study deviations from different types of symmetry (which can be attributed to fluctuating asymmetries), certain differences between homodynamic structures, deviations from fractal in the pattern of various morphologic structures, differences between the monozygotic twins and other manifestations of a chance ontogenetic variability [2,11-13,21,29-33]. The use of monoclonal organisms seems to be perspective for developmental instability study [30].

The most widely used indicator is the value of fluctuating asymmetry of bilateral morphologic structures. Usually, this form of asymmetry is opposed to directional asymmetry and antisymmetry. They most commonly are significant morphologic differences between the sides that are strictly genetically determined [34-37]. An overview of rich experience of selection for various traits in Drosophila reaches the conclusion that it is known the only one unsuccessful attempt to transform of fluctuating asymmetry into directional one-selection leads only to an increase in the magnitude of the fluctuating asymmetry [38]. This result is an evidence of the different nature of these phenomena. If directional asymmetry is associated with the determination of directed changes in morphogenesis, then fluctuating asymmetry is associated with the characteristic of stability of a developing system. Developmental noise can be taken into account not only from the absolute symmetry, but also from a certain directional asymmetry. Some tendencies for bimodality of the distribution of signed differences between the character values at different sides of the body (which commonly is regarded as evidence of antisymmetry) may appear due to the fact that identical independent realization of the trait on the left and on the right becomes unlikely in case of a strong imbalance of the developing system due to increasing genetic or environmental stress and may disappear when it is eliminated [5,39-41].

The study of fluctuating asymmetries involves evaluation of the differences in the values of the character on the left and on the right sides of the body. For this, various morphologic features suitable for accurate accounting can be used. Regarding a qualitative trait this means taking into account the very fact of the dissimilarity of the phenotypic realization of the trait on different sides of the body. For a meristic character, the asymmetry value is determined by the difference in the number of structures on the left and on the right. For a plastic feature, the asymmetry value is calculated as the difference in the measurements on the left and on the right, divided by the sum of the measurements on both sides (in order to level the dependence of the asymmetry value on the value of the feature itself). Statistical analysis of these indicators can be carried out both at the level of average values and 
the variance, using both parametric and nonparametric methods. Possible scaling effect should be specially analyzed in fluctuating asymmetry variance study [29,42].

For a more reliable assessment of the overall developmental stability, it is better to use a number of morphologic characters [40,43-45]. This involves the use of integrated indicators of developmental stability. For qualitative and meristic traits, the simple and most reliable measure is the average frequency of asymmetric manifestations per character (as an additional measure for meristic characters, the average difference between the sides can be used). For plastic features, it is possible to use the average value of the scaled difference between the sides to the feature $[5,46,47]$.

These indicators give an integrated characteristic of fluctuating asymmetry for all the considered features. They are significantly less than other indicators depending on the magnitude of the specific difference between the sides and some extreme values. This approach eliminates many difficulties associated with the analysis of the variance, due to its high sensitivity to the normality of the distribution and individual deviating variants; and the mean absolute difference between the sides, due to the dependence of the asymmetry on the value of the character; or the value of the correlation between the sides, the estimate of which in to a greater degree reflects the ratio of the magnitude of the asymmetry with the range of the total variability of the investigated trait [5]. In case of particular interest in a variance analysis the generalized fluctuating asymmetry index, based on a standardize generalized variance can be recommended [48]. Geometric morphometrics approach is used for an integrated shape assessment of a morphologic structure [11,12,33].

Certain information on developmental stability can also be obtained from the total phenotypic variability (which, in the case of bilateral symmetry, can be estimated from the variance of the sum of the values of the trait on two sides of the body). Due to the uncertainty of the significance of its various components (including genetic, environmental and ontogenetic ones), it can be used by comparing with the value of ontogenetic variability (variance of the difference in the value of the trait on the left and on the right). If all the observed diversity is associated only with the manifestation of ontogenetic variability, the variance of the sum is equal to the variance of the difference and the correlation coefficient between the sides is zero. With the increasing role of other forms of variability, the variance of the sum is significantly higher than the variance of the difference with a positive value of the correlation coefficient $[17,30]$.

Since the actual phenodeviants, as obvious disruptions of development, are quite rare, the frequency of small phenodeviations-as minor deviations from the most common conditionally normal pattern of various morphologic structures-can be used as an additional indicator of developmental stability. An integrated indicator can also be used here, the average frequency of such deviations per character [5].

A specially conducted analysis indicates that in the presence of changes in the stability of development, the effect can be detected using different approaches (including analysis of the frequency of asymmetry, the absolute and scaled magnitude of the difference between the sides, estimates of average values and variances, as well as the frequency of small phenodeviations, using parametric and nonparametric methods) [49].

The calculation of the values of used integrated measures per character makes it possible to compare the data obtained for different characters. The estimates obtained for individual characters with different levels of variability and asymmetry will be different, but when using a number of characters, such integrated estimates are comparable. For example, estimates of developmental stability obtained for craniological characteristics (as the number of foramina on different elements of the skull) turned out to be similar not only for close species, but also for representatives of different orders of mammals [50]. Such a result can only be obtained by analyzing features with a similar range of variation.

With the accumulation of a sufficiently large amount of data to assess the degree of identified deviations, their place in the whole range of possible changes in the indicator, an average frequency of asymmetric manifestations per character, it is possible to develop a point scale. For this, the values of the 
indicator corresponding to the conditionally normal background state, under optimal developmental conditions in the absence of obvious stressful effects, are taken as the first score (conditional norm). Values corresponding to the critical state, in cases of severe stressful effects with a clear adverse effect on viability, are taken as the fifth point. The entire range between these threshold levels is ranked in ascending order of indicator values. Summing up the data for a number of independent indicators, we actually get an integral estimate, which in essence is a point estimate of changes in the state of the organism according to the level of developmental stability. Such scoring systems have been developed and used for a number of plant and animal species [50].

It should be noted that the main limiting factor for the wide use of fluctuating asymmetry indicators is the presence of morphologic structures for the object under study that can be used to develop a system of characters suitable for unambiguous accounting. This determines the possibility of obtaining comparable data by independent research groups. As an example, we can give an integral indicator of developmental stability for birch, which was recommended for environmental quality rationing [41,51,52]. As the practice of using the scale shows-in some cases values can be obtained both above and below the considered range of the integrated indicator-but the basic range suggested covers the main changes in the values on the way from the conditionally normal to critical state [53].

Thus, fluctuating asymmetry study assumes an assessment of the level of developmental noise within the backlash allowed by natural selection as a characteristic of the state of the developing system.

\section{Experimental Study of Fluctuating Asymmetry: Genetic and Environmental Impacts}

The definition of fluctuating asymmetry as a developmental noise has led to the question of the possibility of revealing its dependence on any factors [2]. When analyzing the genetic dependence of the fluctuation asymmetry, it was suggested that it depends on the general characteristics of the genotype, including the level of heterozygosity and genetic co-adaptation [2,3,5,11,54-63]. At the same time, with the obvious dependence of the fluctuating asymmetry of various characters on the homozygosity of some loci, this effect is not observed at other loci. Certain changes in chromosomes or even individual loci can lead to a deterioration of developmental stability, expressed in an increase in the asymmetry of different characters. It was shown that an increase in homozygosity may not lead to tangible changes in the state of the organism and the stability of development. While maintaining optimal development conditions and eliminating adverse alleles, homozygous individuals can be characterized by high viability [21,64]. A scheme of the dependence of developmental stability on types of crossing can be presented as the following. Crossing of close forms with high developmental stability does not lead to a change in this characteristic. When crossing close highly homozygous lines with low developmental stability, developmental stability is improved by removing inbred depression. When crossing distant forms, significantly genetically distinct, adapted to different conditions, it leads to a decrease in developmental stability. In this case a decrease in developmental stability is observed with an increase in heterozygosity [65]. Thus, despite the increase in asymmetry noted under certain conditions with high homozygosity, in a more general form, the relationship between developmental stability and genotype can be formulated as a dependence on genetic co-adaptation.

Assessment of the influence of environmental factors led to the conclusion about the disturbance of developmental stability under environmental stress. A decrease in developmental stability was found when exposed to lower and higher temperatures for a number of species of insects and fish [47,55,66,67], exposure to unusual temperature conditions during prenatal and early stages of postnatal ontogenesis in mammals [68]. An experimental assessment of the dependence of developmental stability on incubation temperature for sand lizard Lacerta agilis showed that the minimum fluctuating asymmetry for the meristic pholidosis characters occurs only at a certain temperature regime, increasing both with decreasing and increasing temperature, which indicates a decrease in developmental stability $[5,19,69]$ (Figure 1). A decrease in the stability of development in different species under different types of environmental stress has been shown, including an increase in density, exposure to various chemical pollutants [11,70-72]. A decrease in development stability (an increase in the value of fluctuating 
asymmetry) is a nonspecific reaction to adverse effects of a different nature. It turned out that in assessing the natural factor, for example, temperature, the dependence of developmental instability indicators has the form of a curve with a minimum that corresponds to the optimum. Such data were obtained for various traits related to different morphologic structures, regardless of possible changes in the value of the trait itself. Curves with a minimum in terms of fluctuating asymmetry indicators are observed when the average value of the character itself increases, decreases or does not change in the studied range of conditions $[5,47]$. When assessing adverse factors, the optimum value of which for the developing organism is zero, as in the case of chemical pollution, the dependence takes the form of only one branch of this curve, which corresponds to a decrease in the stability of development as the degree of exposure increases.

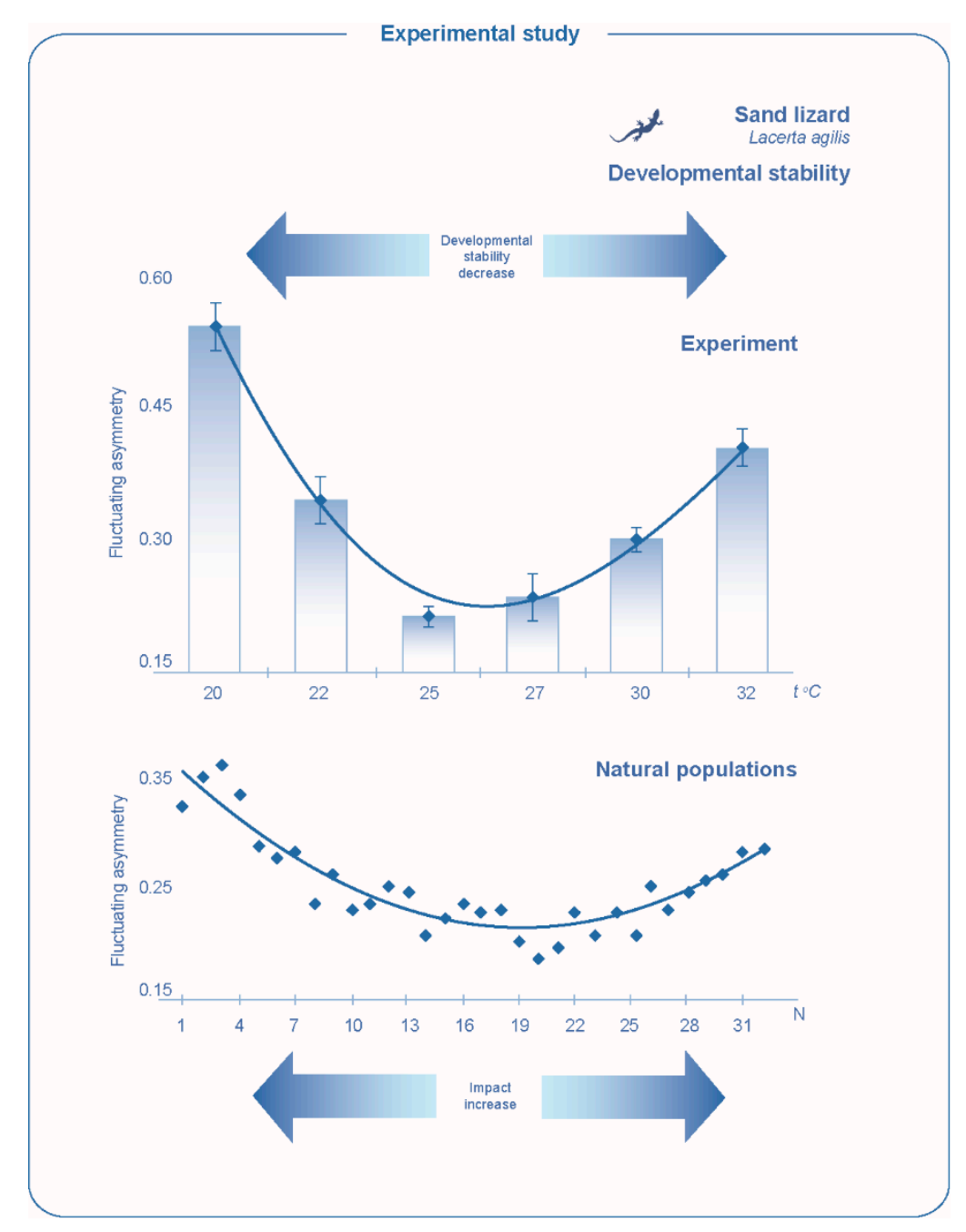

Figure 1. Value of the developmental stability index at different incubation temperatures in experimental conditions and in natural populations. Developmental stability was assessed by the value of the integrated indicator: the average frequency of asymmetric manifestations per character (for 13 characters of pholidosis). $\mathrm{N}$ is the number of samples from natural populations in the European part of Russia (Samples 1-32 are located from the north to the south, from the Novgorod region to the Stavropol region).

The dependence of developmental stability on both genetic and environmental factors can be illustrated by experimental data obtained for representatives of different groups of animals. For the silkworm Bombyx mori, the dependence of fluctuating asymmetry of wing measurements on incubation temperature was analyzed for lines significantly different in the level of heterozygosity [73,74]. A certain level of general heterozygosity (relative to the heterozygosity of the initial line, which was taken as 
100 percent) was obtained and fixed for these lines by meiotic and ameiotic parthenogenesis [75]. It turned out that the dependence of developmental stability on temperature is the same for all lines, but the dependence curves are parallel. A decrease in developmental stability is observed both when deviating from optimal conditions (environmental stress) and with an increase in homozygosity (genetic stress) (Figure 2).

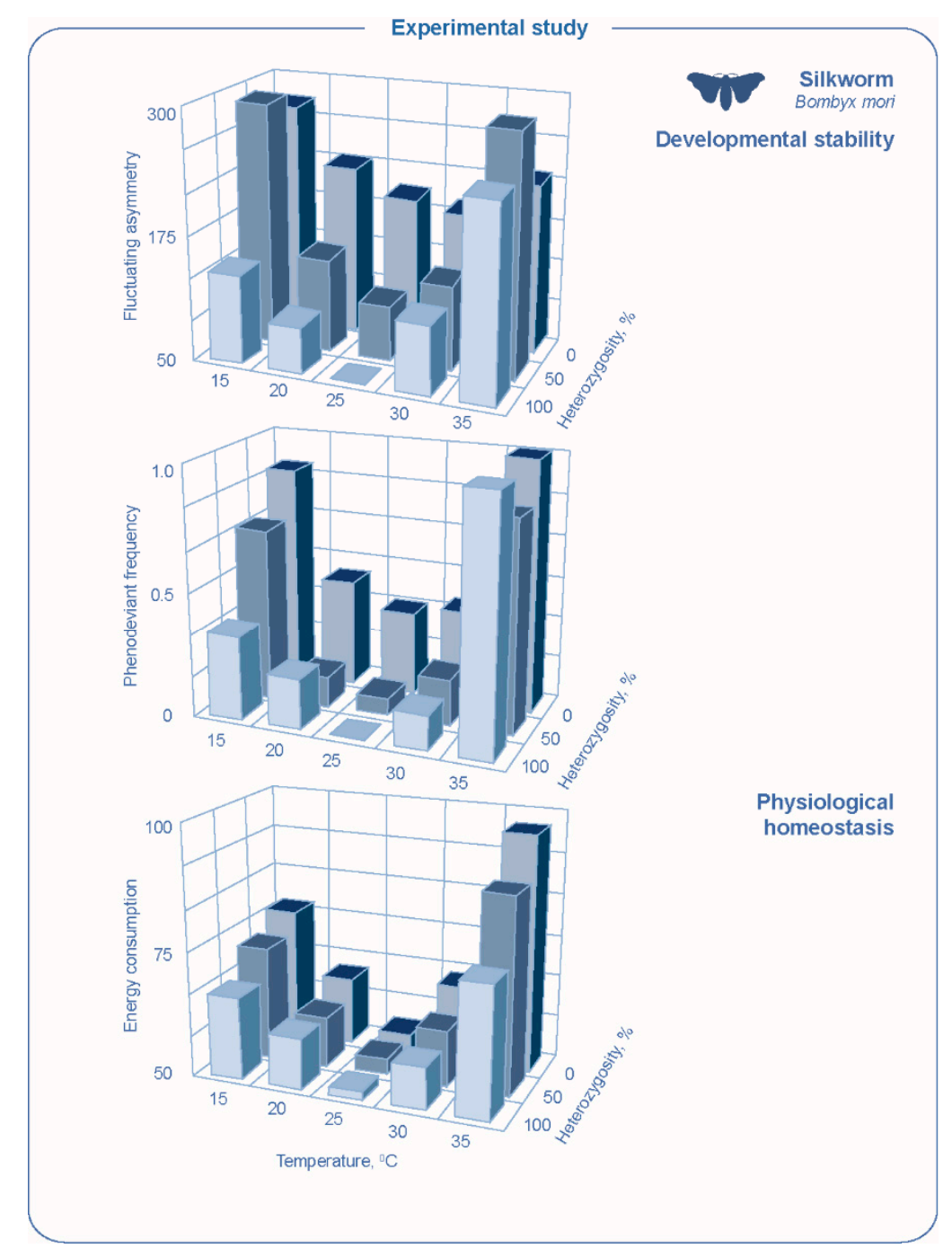

Figure 2. Value of developmental homeostasis indices at different incubation temperature and heterozygosity. Developmental stability was assessed by the value of the integrated indices: the variance of the scaled difference between the sides (the sum of the ranks) (for 22 wing measurements) and the frequency of phenodeviants (individuals with underdeveloped wings). The efficiency of energy metabolism was estimated by the total oxygen consumption during pupae development.

In another experiment on rat inbred laboratory lines Rattus norvegicus, it was shown that homoand heterozygosity at a single locus does not affect developmental stability measured by fluctuating asymmetry of craniological characters. Further inbreeding leads to a decrease in the stability of development. Crossing close homozygous lines with reduced developmental stability leads to increased developmental stability (by removing inbred depression), while crossing distant lines leads to its decrease (due to impaired genetic co-adaptation). Conditions of social stress also lead to a decrease in developmental stability (Figure 3) [72,76]. 


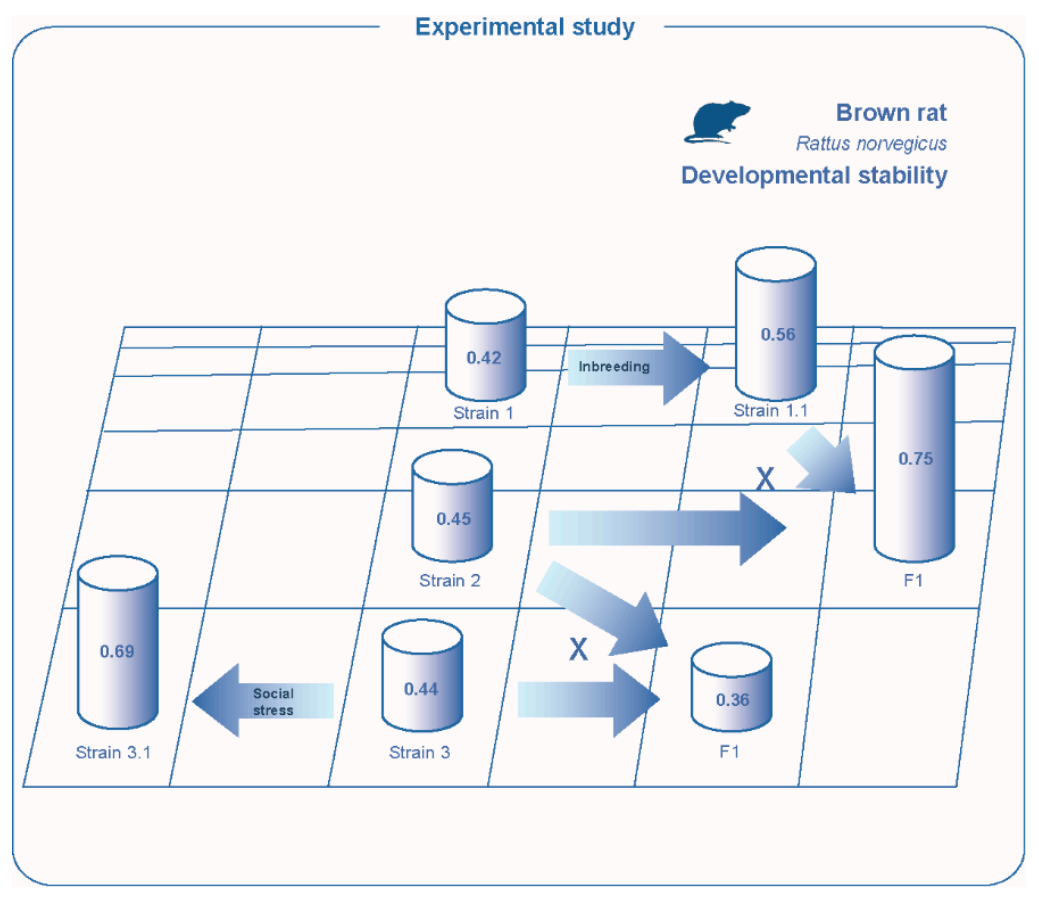

Figure 3. Value of developmental stability index of laboratory lines and their hybrids. Developmental stability was assessed by the value of the integrated index: the average frequency of asymmetric manifestations per character (for 20 craniological characters, number of foramina). Inbreeding leads to developmental stability decrease (fluctuating asymmetry increase). Crossing of close homozygous lines (2-3) leads to developmental stability increase. Crossing of distant lines (1-2) leads to development stability decrease. With social stress, developmental stability decrease is observed.

Thus, developmental stability is dependent on both genetic stress and environmental stress. The response to any adverse effects-both from the genotype and from the environment-proves to be the same. The state of the organism changes-which is indicated by the deterioration of developmental stability. Only by the nature of the factors causing it can be defined as environmental or genetic stress. Stability of development gives an assessment of the state of the organism, which depends both on the power of the system itself (genetic co-adaptation and its possible disruption, genetic stress) and on external conditions (optimum and deviations from it, environmental stress). Stability of development acts as an ontogenetic characteristic of the state of the organism.

\section{Study of Fluctuating Asymmetry in Nature}

The directions of studies of developmental stability in natural populations are determined by the possibilities of detecting changes in the state of a developing organism under genetic or environmental stress.

It is natural to expect that genetic co-adaptation is supported in natural populations. Its disruption can be observed in case of hybridization, in the zones of secondary intergradation of quite genetically different forms adapted to significantly different conditions. The task in this case is to check whether this hybridization leads to a disruption of genetic co-adaptation. Both positive and negative examples are known [5,11,61,77-80], which indicates that the genetic co-adaptation disruption does not occur in any cases of hybridization. Assessment of the development stability just provides an opportunity to answer the question about the possible consequences of such intergradation. Another reason for changes in developmental stability may be a high level of homozygosity. It has been shown that if some decrease in developmental stability due to inbreeding may not yet be accompanied by a change in other fitness indicators, then a more serious decrease of developmental stability is already accompanied by a clear change in viability (due to an even higher level of inbreeding) [81,82]. At the same time, in other 
cases, a decrease in heterozygosity is not accompanied by a decrease in developmental stability [83,84] that indicates that far from any changes in heterozygosity lead to a deterioration in the state of the organism. The study of development stability is a possible approach to assess the situation in each case. A decrease in the stability of development can be observed due to genetic changes in the way of adaptation to new conditions. Assessment of developmental stability revealed a change in the state of the organism in case of coadaptation disturbance when it becomes possible to exist when exposed to an insecticide Thus, the heterozygosity and the disruption of coadapted genomes can play a big role in developmental instability [39,61].

In relation to population studies, the most promising is the assessment of developmental stability as an indicator of environmental stress.

Temporal variation in the level of developmental stability can occur under increase of adverse impact of environmental conditions and an anthropogenic impact in particular [85]. Developmental stability estimates proved to be stable under stable environmental conditions in both cases in the reference sites and under the constant level of adverse impacts [53,86]. The study of developmental stability is of interest in assessing possible changes in the state of the organism during population dynamics. It has been shown that in cyclic mammalian populations of the common shrew Sorex araneus in Central Siberia for which an autoregulatory mechanism of population dynamics is assumed, there may be a negative relationship between developmental stability measured by fluctuating asymmetry of scull characters and abundance. At the peak year, due to overpopulation, there is a decrease of the stability of development (indicating a change in the state of the organism), leading to a subsequent reduction in the number. In a non-cyclic population in Southern Finland, the situation can be significantly different. When the threshold level of density is reached, a decrease in development stability can be observed against a background of high abundance, while under adverse external influences, a decrease of development stability can occur when the abundance decreases (Figure 4) $[49,87,88]$. This situation also holds for invertebrates, the number of which increases under favorable external conditions against the background of high developmental stability [5]. Thus, against the background of a high population size, a significantly different state of the organism can be observed due to different mechanisms of population dynamics. The results obtained indicate the prospects of this approach for identifying the mechanisms of population dynamics in each particular case: a positive relationship between development stability and density indicates a greater role for environmental factors, a negative relationship corresponds to the assumption of the stressful effect of overpopulation.

Changes in population dynamics under conditions of modern climatic instability [89] bring another challenging task for developmental stability study. Under these conditions, the cyclic dynamics of small mammals in Central Siberia is replaced by fluctuations [90]. If in the previous period, under conditions of climatic stability, during four-year population cycles, an increase in population over three years led to a disturbance in the developmental stability (which was accompanied by a change in cytogenetic homeostasis) at the peak year, then under present conditions there are some fluctuations in the population, which are likely to a greater extent determined by climate, are not accompanied by such changes in developmental stability (Figure 4).

The decrease in development stability is an indicator of the deterioration of the organism condition at the ecological periphery of the species range [5,91-93]. The presence of such an effect has been demonstrated with various examples in relation to different groups of living beings. A decrease in developmental stability measured by fluctuating asymmetry of the leave characters was revealed with increasing altitude and worsening growing conditions for plants, silver birch, Betula pendula and alder, Alnus alnobetula (Figure 5) [11,51,94]. Decrease of developmental stability was detected at the northern and southern ecological periphery of the range by a sand lizard. Moreover, the revealed pattern of interpopulation differences is consistent with the results of an experimental analysis of the dependence of developmental stability on temperature (Figure 1) [8,61].

A decrease in developmental stability (measured by skull characters) was found at the northern border of the range and in mountainous conditions for a number of mammalian species, including both 
rodent and insectivorous species, northern red-backed vole, Myodes rutilus and Siberian large-toothed shrew, Sorex daphaenodon, (Figure 6) [95]. Environmental peripheral conditions may occur in different parts of the range. Plants are especially indicative in this respect-significant changes in the state of which are observed everywhere against the background of differences in growing conditions, including soil characteristics, competitive relationships and shading conditions $[11,51,94]$. For a number of species of small mammals, differences were revealed in terms of developmental stability in different biotopes [96,97]. Deterioration of developmental stability is observed in fish populations introduced into new habitats [5]. In addition, today environmental peripheral conditions can arise everywhere as a result of increased anthropogenic impact $[11,19,66,95,98]$.

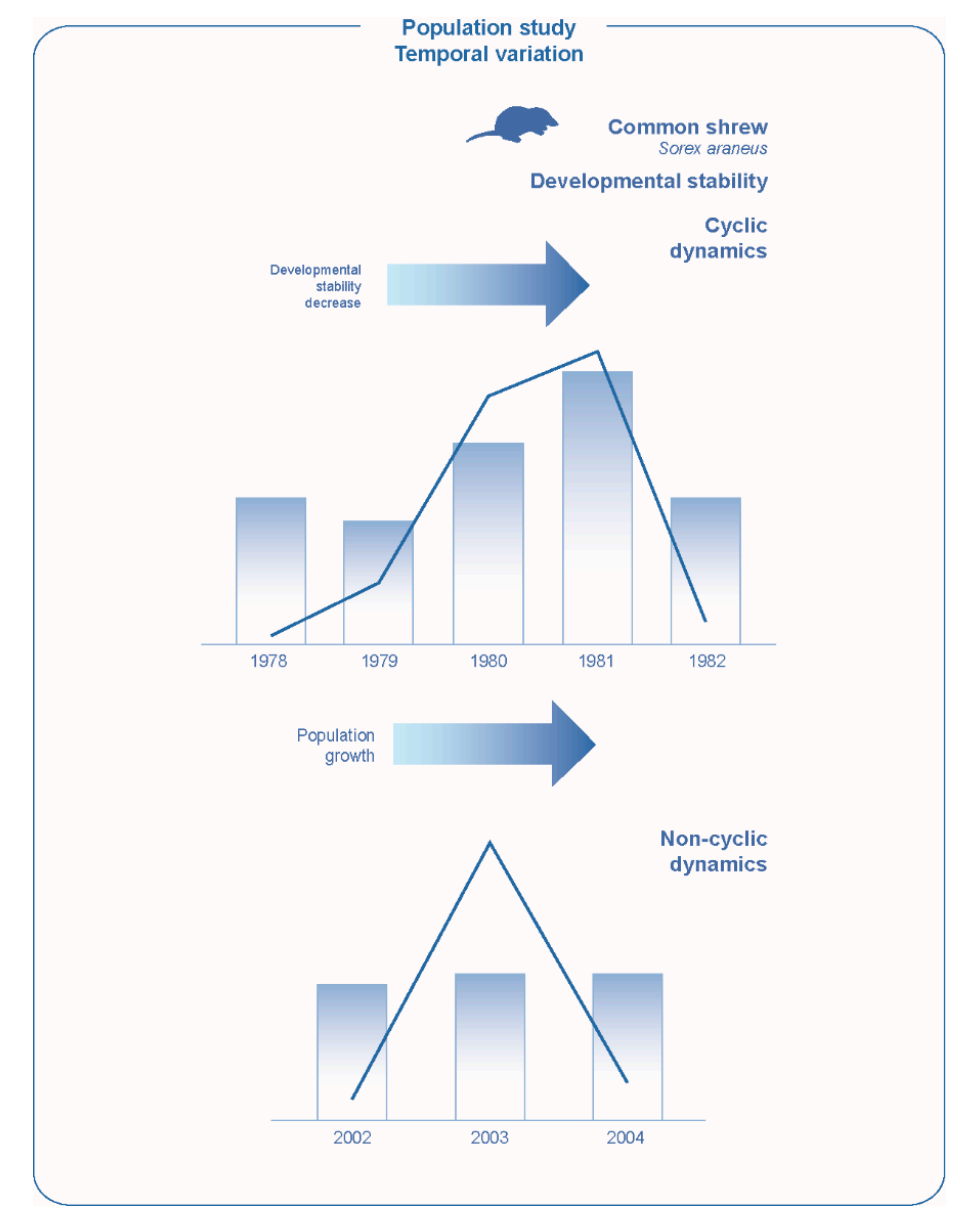

Figure 4. Value of the developmental stability index at various population density. Columns-developmental stability was assessed by the value of the integrated index: the average frequency of asymmetric manifestations per character (for 10 craniological characters, number of foramina); Line-population density (the number of animals caught per 100 traps/day during the summer season).

An approach seems also promising for assessing the consequences of those changes that are beginning to occur everywhere as a result of global climate changes. This is especially pronounced in high altitude conditions, where new populations appear in the places where glaciers melt. An analysis of developmental stability (measured by leave characters) gives an answer about the state of invaders (Figure 7) [94]. The species studied in this case, silver birch, is widespread and common in temperate climates, mainly in the forest zone, its distribution is limited to the high temperature zone. This suggests that the dependence of the development stability for this species on the height in the study area (Krasnodar Region) will have the form of a curve with a minimum. At a low altitude at high temperature and humidity, in conditions close to subtropical, one can expect a developmental stability decrease 
(high fluctuating asymmetry). With a rise in altitude in the mountains in the forest zone there should be an increase in development stability (fluctuation asymmetry decrease). At high altitudes, when approaching the zone of alpine meadows, we can again expect a deterioration in the stability of development. It is such a picture of the change of developmental stability index that is observed in the studied populations in the gradient of the change in height.

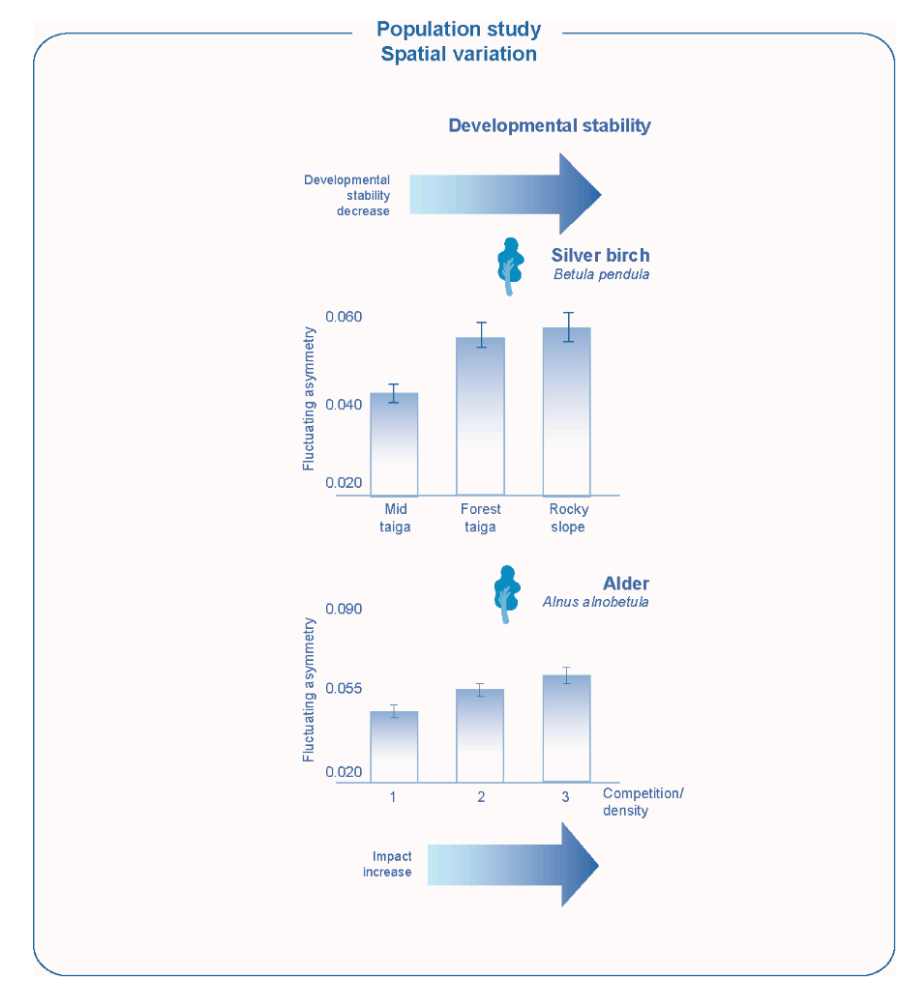

Figure 5. Value of the developmental stability index in different biotopes. Developmental stability was assessed by the value of the integrated index: the average scaled difference between the sides per character (for 5 leaf measurements). Developmental stability decrease is observed in (upper) extreme habitats and (lower) with competition/density increase in different types of forests (1-3).

Thus, developmental stability acts as an operational criterion for determining optimal habitats for the species under study. The approach seems promising for identifying the role of geographical isolation and environmental conditions in the pattern of intraspecific phenotypic diversity. This is especially actual for widespread species, quite common and numerous in different landscape and climatic zones. Against the background of significant differences between certain parts of the species range, which are likely to have the microfilogenesis origin, within each of these areas a similar dependence of developmental stability indicators on climate characteristics and habitat conditions can be traced (such an analysis was carried out for insects and reptiles [5,19].

The pattern of intraspecific variability is dependent on the specific situation. Populations under similar conditions - even substantially spatially remote from each other-are characterized by a similar level of developmental stability. At the same time, its deviations can be observed with a significant change in the environment even in a small space. This suggests that many populations of the species, despite some differences, have a similar optimum in development stability, which makes it possible to reveal populations that exist under non-optimal conditions. Each species is adopted for the certain range of environmental conditions, and on the periphery of the species range those populations where a decrease of developmental stability is a "payment" for existence under new conditions can be identified. 


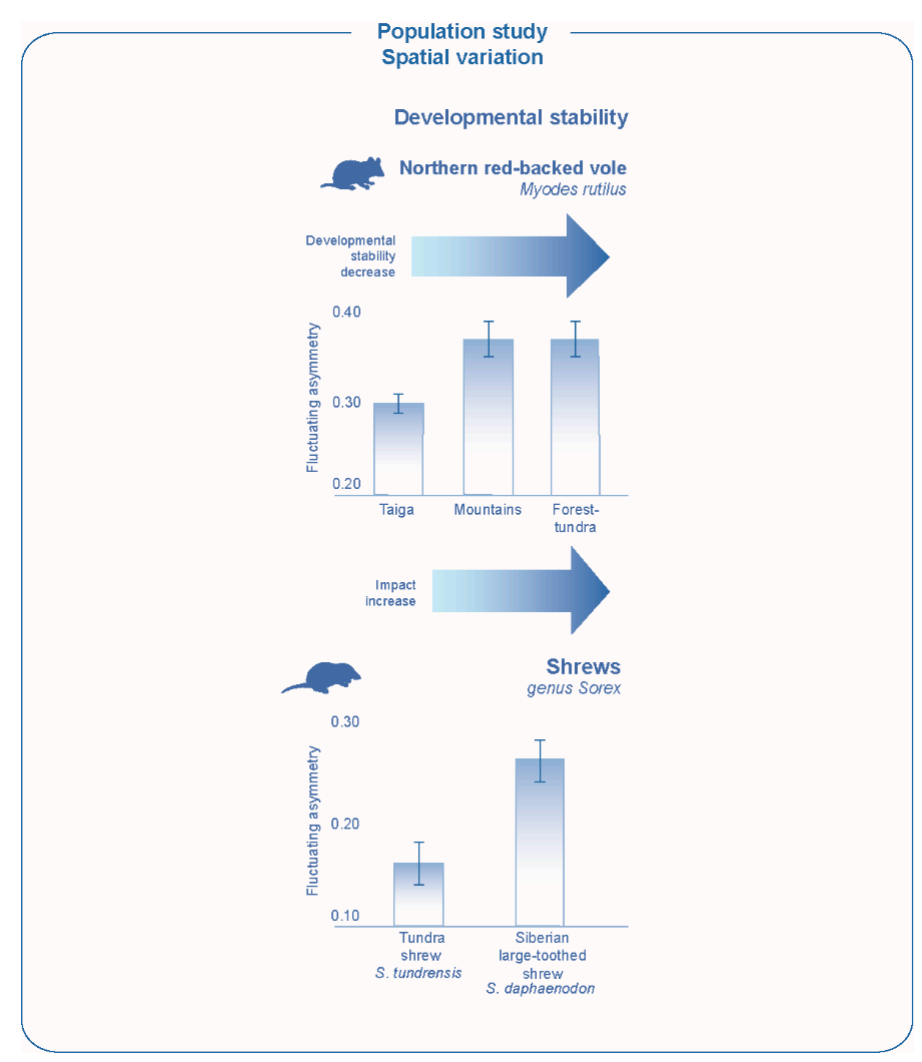

Figure 6. Value of developmental stability index in different parts of the species range and in the sympatric populations of shrews in the forest-tundra. Developmental stability assessed by the value of the integrated index: the average frequency of asymmetric manifestations per character (for 10 craniological characters, number of foramina).

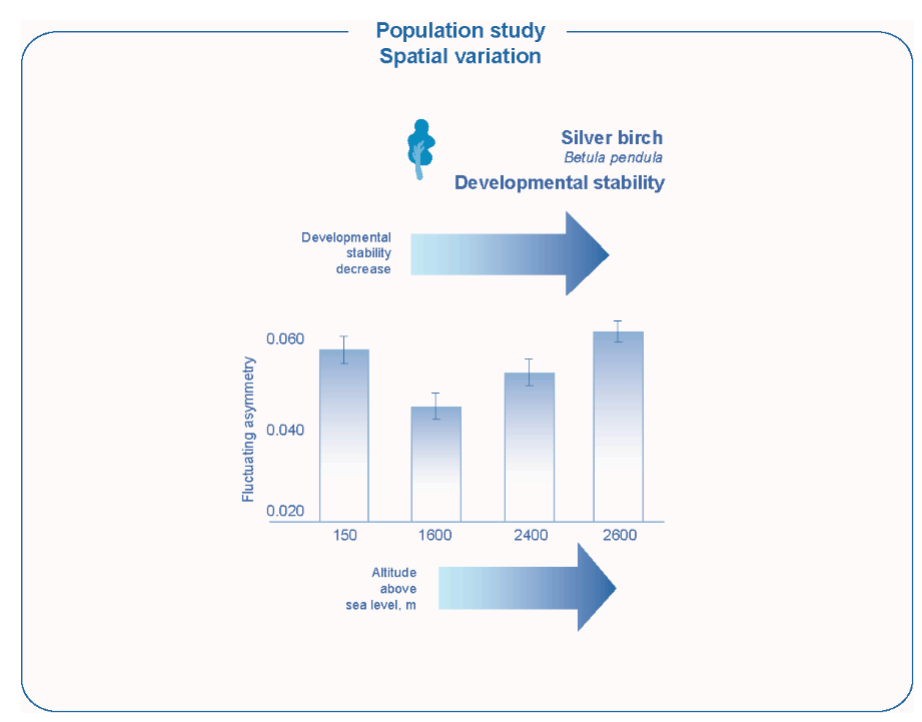

Figure 7. Value of the developmental stability index at different heights. Developmental stability was assessed by the value of the integrated index: the average scaled difference between the sides per character (for 5 leaf measurements). The dependence of the instability index of birch on the altitude above sea level in the Krasnodar Region has the form of a curve with a minimum (an increase in the value of the index in the conditions of the ecological periphery of the species range). At low altitude at high temperature and humidity, a developmental stability decrease is observed (fluctuating asymmetry increase). In the mountain forest zone, there is a developmental stability increase. At a higher altitude, when approaching the zone of alpine meadows, a developmental stability decrease takes place again. 
Comparison of sympatric populations of closely related species provides an opportunity to assess the difference in their reaction to the same environmental conditions. Such a different reaction means that the same conditions are optimal for one and not optimal for another species. The presence of such differences indicates that due to certain adaptive changes the population of one species can successfully exist in these conditions that have an adverse effect to another species. Such differences in developmental stability (for pholidosis characters) were revealed for sympatric populations of two lizard species of genus Lacerta: L. agilis and L. vivipara at the northern and southern boundaries of the species ranges (Figure 8). Similar data were obtained on a number of models, including some representatives of insects, reptiles and mammals [5,17,19,69,95].

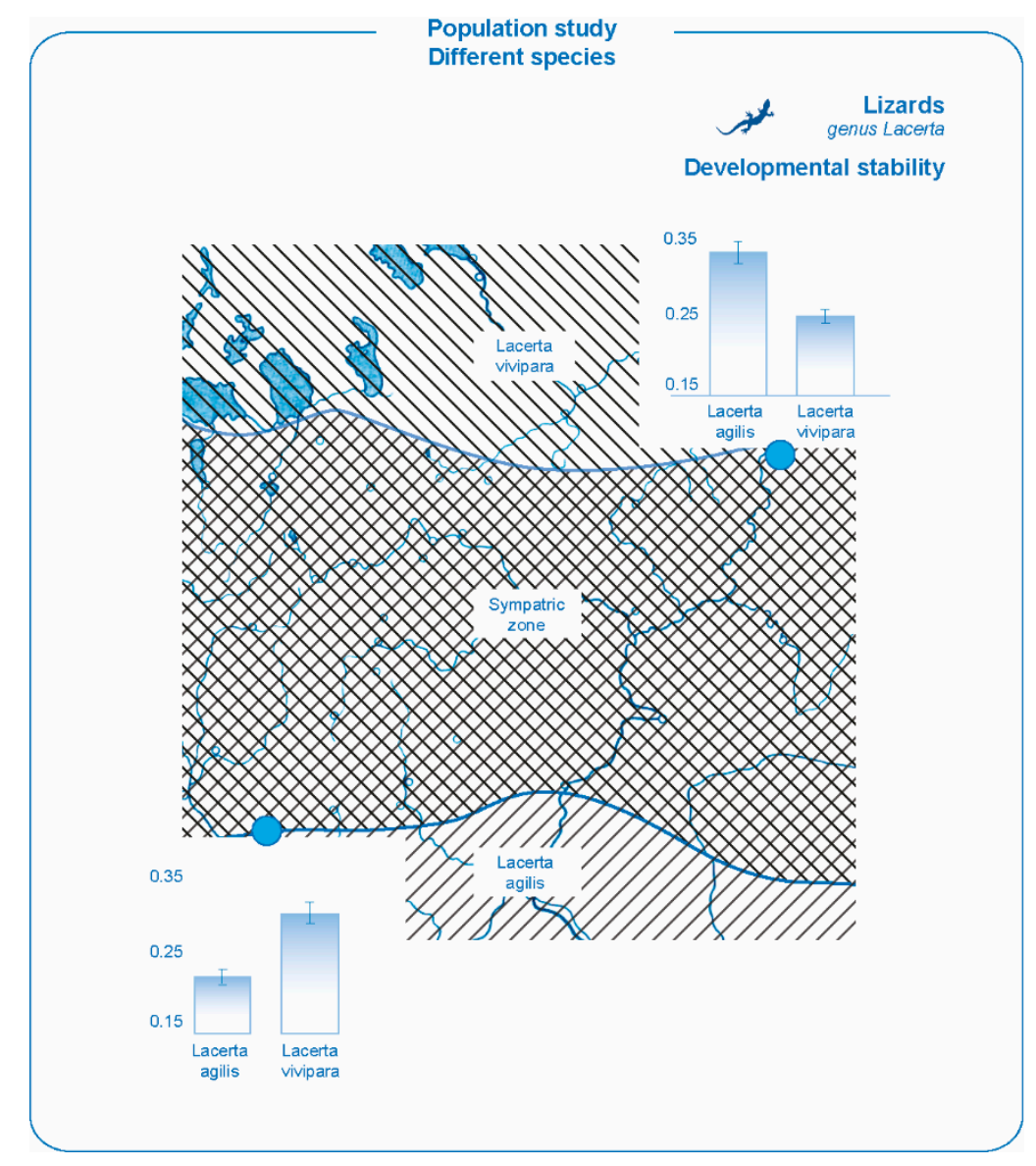

Figure 8. Value of developmental stability index in sympatric populations of two lizard species. Developmental stability was assessed by the value of the integrated index: the average frequency of asymmetric manifestations per character (for 13 characters of pholidosis). Developmental stability decrease (high fluctuation asymmetry) takes place at the ecological periphery of the species range: (upper) in the northern population of L. agilis and (lower) in the southern population of L. vivipara.

\section{Application of Fluctuating Asymmetry Study in Developmental and Population Biology}

It is important to evaluate the significance of the study of fluctuating asymmetry indicators to characterize the nature of the observed phenotypic diversity and the state of biologic systems.

Despite the importance of an estimate of the nature of the observed phenotypic diversity in population studies, solving this problem is usually difficult. Against the background of the fact that genotypic diversity is usually implied as the main cause of phenotypic diversity, as the experience of a special assessment of fluctuating asymmetry has shown, a significant proportion of the total phenotypic variation in natural populations can occur from developmental noise [11,19]. 
The ratio of different forms of variability for bilateral characters can be represented by comparing the variance of the sum of the values of the trait on two sides of the body, which can be considered as an estimate of the total phenotypic diversity and the variance of the difference, as an estimate of developmental noise. Their ratio may be different. The proportion of the variance of the difference in the variance of the sum indicates the role of developmental noise in the observed level of total phenotypic diversity. An increase in the total phenotypic diversity observed under changing conditions, which is not limited to an increase in the level of noise, can be considered as evidence of the genotype-environment interaction, which is a manifestation of differences in the canalization of development $[17,99]$.

It is natural to expect that noise is expressed in the development of any phenotypic characters of an organism. The similarity of changes in the total phenotypic diversity of bilateral morphologic characters caused by fluctuating asymmetry increase with changes in the diversity for other characters, for which there is no possibility for a direct assessment of the noise level, can be considered as a rough estimate of the nature of the observed changes for these characters too. A simultaneous increase in the frequency of small phenodeviations also supports the role of developmental stability decrease in the observed increase of phenotypic diversity [5].

An increase of developmental noise under stress could be a cause for an increase of the total phenotypic diversity [93] or indicate a decrease of other kinds of variability in case of the same level of total diversity. In the study of population dynamics, it was shown that while in the non-cyclic population of a common shrew in Southern Finland, the level of ontogenetic variation varies parallel to the level of total phenotypic diversity, in the cyclic population of Central Siberia ontogenetic variability, which increases sharply under stress, largely determines phenotypic diversity at the peak year of the population cycle $[100,101]$ An increase in the level of noise observed at the ecological periphery of the species range of the sand lizard is observed against the background of the same level of total phenotypic diversity, indicating a decrease of the proportion of other forms of variability compared to populations in the center part of the species range (Figure 1) $[19,69]$.

To assess the mechanisms of microevolutionary transformations, it is important to consider two aspects of development homeostasis: not only development stability, but also canalization or plasticity of development [2,5]. In this case, an experimental assessment of what is happening in nature is possible, taking into account certain environmental factors. The easiest way to do this is to incubate offspring from gravid females obtained from different parts of the species range at different temperatures [102]. As was shown, the dependence of the studied morphologic characters on temperature may be similar for different intraspecific forms and even different species, but the dependence curves run in parallel, indicating the genetic determination of the new reaction norm and are shifted in the direction of modification changes. Such data can be considered as an evidence of the act of the mechanism of the emergence of the interpopulation and interspecific differences through the genetic determination of a new reaction norm that arises on the basis of a modification response. When assessing the stability of development, it turned out that the value of the trait-which is accompanied in one form by low stability of development-in another takes place against the background of high developmental stability. The examples of comparison of sympatric populations of different species in nature are evidence of the microevolutionary process, as a result of which initially non-optimal conditions became optimal (Figure 8) [17,69]. Thus, the mechanism of evolutionary transformation may begin not with genetic, but with ontogenetic changes. If the initial situation is characterized by high development stability against the background of optimal conditions and high genetic co-adaptation, under the stressful effect of the new conditions, a decrease in development stability (environmental stress) is observed. With the long-term existence of a population under these conditions, adaptive genotypic changes are usually observed, but homeostasis does not yet improve due to a disruption of previous genetic co-adaptation (genetic stress). In the course of further transformations, it is possible to achieve a new genetic coadaptation and restore a high level of homeostasis. In this case, the optimum changes. This process, apparently, does not always go through to the end. Intermediate situations are observed on the ecological periphery of the species range $[4,5,91,93]$. The difference in the level 
of developmental stability between sympatric populations of closely related species indicates the possibility of a transition from disturbance to the restoration of developmental stability as a result of the adaptation process. The sympatric zone, being the ecological periphery causing a disturbance of developmental stability, for one species is the optimal habitat, characterized by high developmental stability, for another species.

A parallel experimental and population analysis of the canalization and plasticity of development provides an opportunity for an approximate assessment of the nature of the observed pattern of interpopulation variation. The correspondence of experimentally revealed trends of phenotypic changes with changing developmental conditions to the observed pattern of intraspecific variability and climatic features on the species range indicates the role of the environment, the discrepancy testifies to the role of the microphylogenetic features of the certain populations of the species in the studied areas of the species range. Against this background, the estimation of fluctuating asymmetry provides an ontogenetic characteristic of populations condition [5].

In the study of developmental stability, assessed by the fluctuating asymmetry of individual characters, it is crucial to answer the question of the significance of the detected changes for developing organisms under study.

A peculiarity of fluctuating asymmetry, as evidence of developmental noise, is that the differences between the sides for close, even highly correlated, characters are usually not related. An exception can be seen in the case of a study the characters set as the measurements of the parts of the same structure, as a wing of insects or a skull of mammals. Fluctuating asymmetry in size and shape at the level of the whole structure could lead to an appearance of a positive correlation of the signed differences between the sides for the internal measurements inside the structure [11,32,103].

At the same time, at the level of population estimates, the asymmetry of different characters can be highly correlated, being, in fact, an integral population indicator $[4,5]$. The consistency of their changes is just evidence that in the studied group of samples there are actually differences in the overall development stability. Conversely, in the absence of such differences, the deviations of the asymmetry values for individual characters are random and turn out to be inconsistent. Consistent changes in the magnitude of the asymmetry can be revealed in case of adverse impact not only within the particular group of characters, but also for different groups of characters. Such an effect was observed for craniological and dermatoglyphic characters in the case of chemical intoxication in American mink Neovison vison (Figure 9) [71].

Another important task for a developmental stability study in to answer the question of how much the changes revealed, in this case, are associated with changes in other indicators of the state of the organism, which from different perspectives give a characteristic of developmental homeostasis. It was shown that a decrease of developmental stability is accompanied by a similar change in the physiological measure of homeostasis characterizes the energy metabolism, the total oxygen consumption necessary for a certain stage of development (Figure 2) [73,74]. In experiments on social stress in rats, it was shown that an increase in the asymmetry of skull characters is accompanied by a change in immune status [72,104]. Shading in plants, silver birch, affects developmental stability and photosynthesis (Figure 10) [105]. Examples of such consistent changes in different indicators of the homeostasis were obtained by studying the effects of various anthropogenic factors [106]. Thus, we can talk about coordinated changes in various parameters of the organism, which characterize development homeostasis from different perspectives. This consistency is evidence of changes in homeostasis of development under genetic or environmental stress. It means that the study of developmental stability may not only characterize morphogenetic processes, but also the state of the organism. 


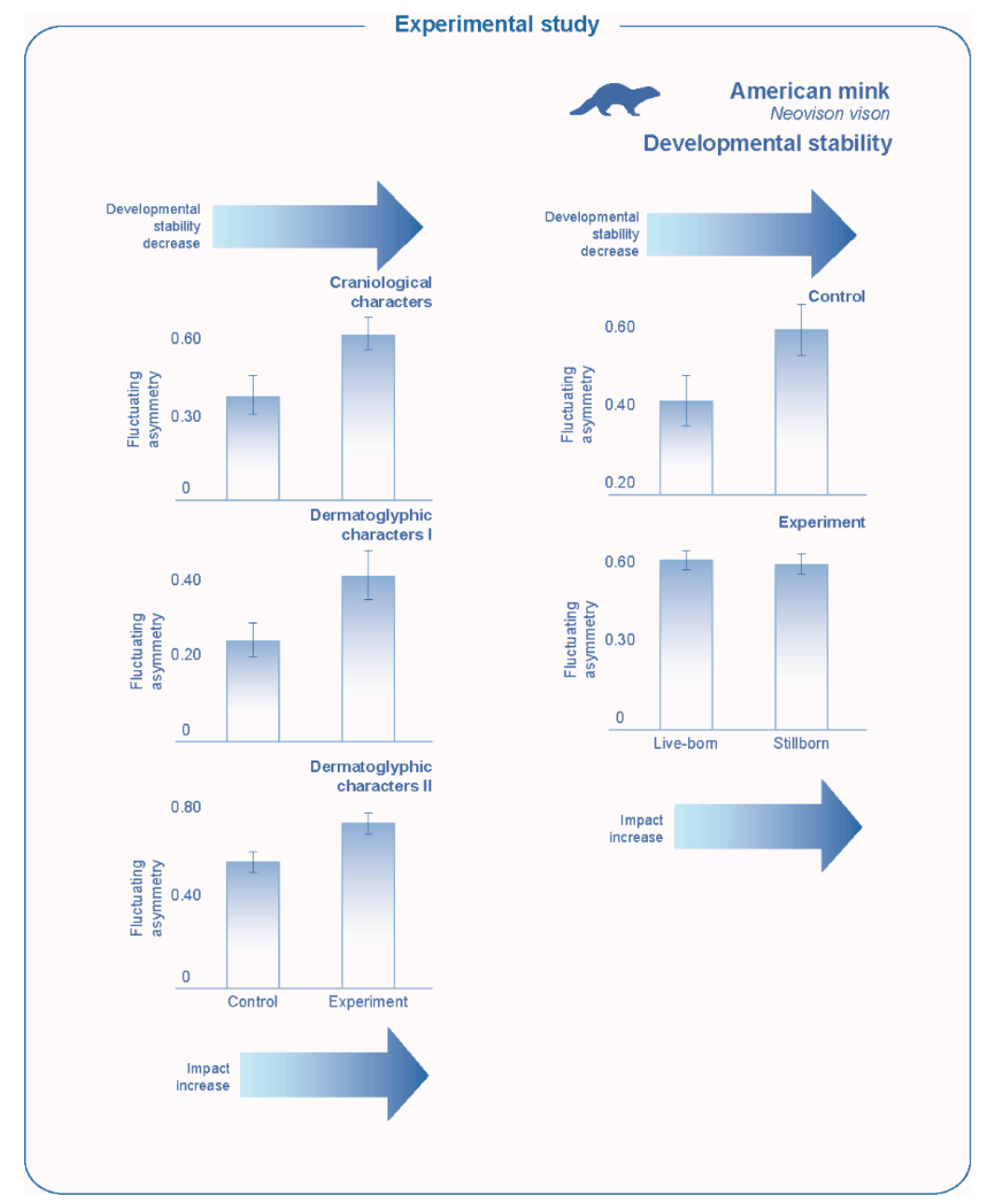

Figure 9. Value of the developmental stability index of the offspring of intoxicated females (PCBs). Development stability was assessed by the value of the integrated index: the average frequency of asymmetric manifestations per character (for 14 characters, including 7 craniological characters, number of foramina and two groups of dermatoglyphic characters: 3 characters of the number of palatine ridges (1) and 4 characters of dermatoglyph of the nasolabial mirror (2)).

Examples of revealing the connection between indicators of developmental stability and commonly used indicators of fitness were obtained [8,107-109]. Developmental stability estimates are correlated with the actual population indicator, the breeding success. Such a correlation was found during the population cycle in small mammals [49]. Some advantages of the approach can be shown by the example of the results obtained from an experimental assessment of the effects of pollution [71]. If in the reference group the developmental stability in stillborn American minks was significantly lower (high asymmetry) than in liveborn minks, then in the experimental group both subgroups had a similarly high level of developmental disorders (Figure 9). Thus, a decrease of the stability of development occurs when an organism condition deteriorates due to various reasons but is not the cause of its death. This simultaneously indicates the sensitivity and significance of this characteristic. If the phenotypic changes observed, apparently, are within a certain backlash allowed by natural selection, and some changes in the level of ontogenetic noise are only a consequence of some differences in the state of the developing system, then the changes in other parameters that appear may affect the viability of the organism. This opens up the possibility of using this characteristic as an early warning indicator of an organism condition.

At the same time, the relationship between changes in fluctuating asymmetry and changes in such indicators as a growth rate and body size may be different. If under an obvious adverse effect of 
particular factors, it is natural to expect a directional change in these indicators [11,68], under a less significant effect, these indicators may not show the expected effect due to their primary dependence on other characteristics of the habitat (temperature, food supply and others). The same can be noted for biodiversity indicators. Significant changes in the stability of development can take place against the background of the same biodiversity and the number of individual species. In some cases, even an increase in these indicators can be observed, as in the case of the initial stages of habitat eutrophication.

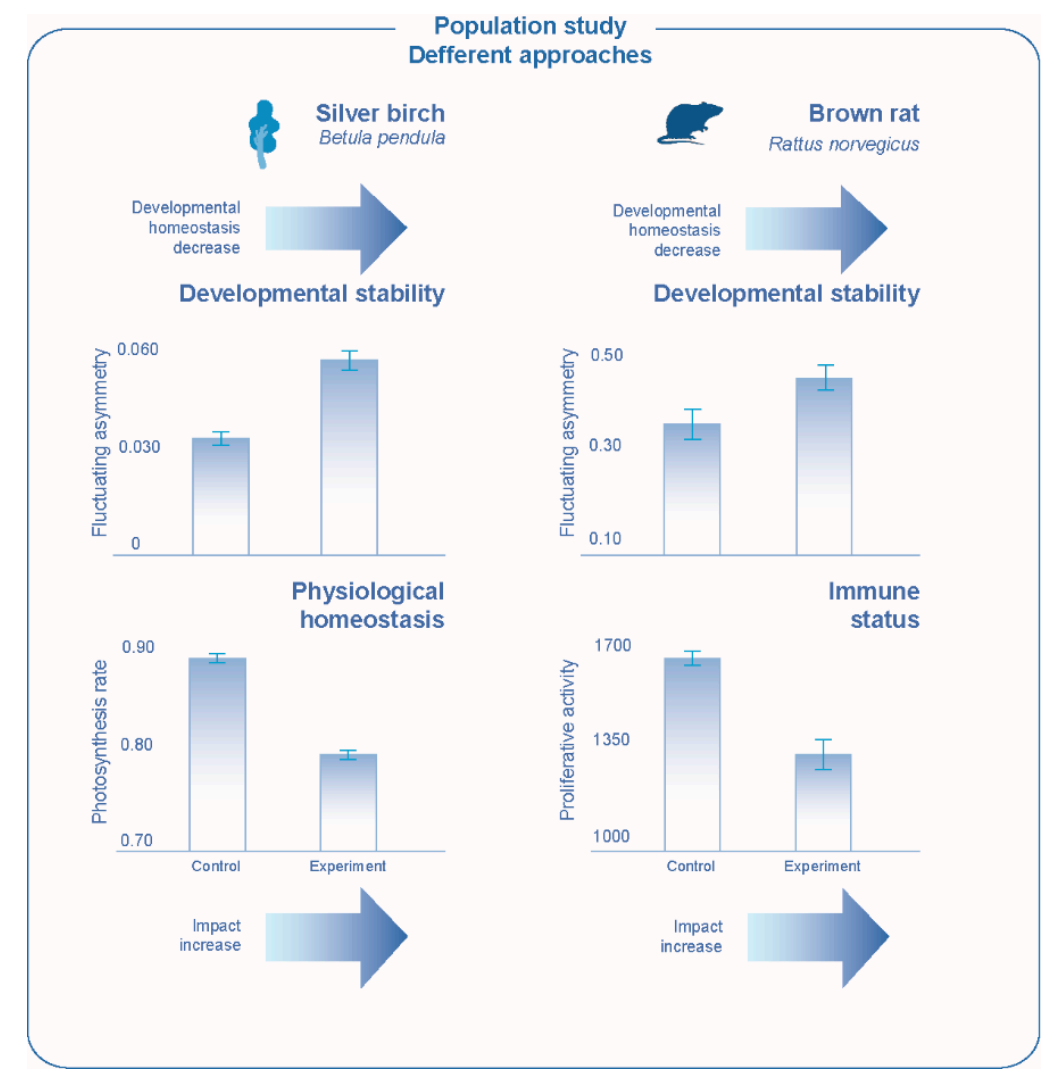

Figure 10. Value of developmental homeostasis indices under shading in plants and social stress in mammals. Developmental stability was assessed by the value of the integrated index: the average scaled difference between the sides per character (for 5 leaf measurements) for plants and the average frequency of asymmetric manifestations per character (for 20 craniological characters, number of foramina) for mammals. The efficiency of photosynthesis was evaluated by the ratio of the variable fluorescence to the maximum. Immune status was assessed by the proliferative activity of lymphocytes.

It is quite natural to expect that if the influence of a certain factor affects a habitat, a similar reaction can be detected for different species. This is especially evident when studying the effects of anthropogenic pollution (chemical or radiation). In this case, deterioration of developmental stability can occur for a wide range of species. The consistency of changes in different indicators for different species evidences the reliability of the result to assess the state of biologic diversity and environmental health [45,52].

\section{Future Prospects for Fluctuating Asymmetry Study}

The prospects for fluctuating asymmetry study are determined by an opportunity to assess the level of developmental noise. Ontogenetic variability related to developmental noise, obscuring the identification of strict determination of phenotypic realization of the genotype, provides a unique opportunity to assess developmental stability, since other commonly used forms of variability, including genetic and environmental ones, are not available for such an assessment. Developmental stability study allows one to characterize the condition of developing systems and to elucidate the role of 
ontogenetic variability in the observed total phenotypic diversity and its possible temporal and spatial variation. Obtaining such information is of interest both to characterize a homeorhesis in developmental biology and to assess an organism condition in population biology. Particularly promising is the development of a population developmental biology approach based on developmental stability study in natural populations for solving various problems in a practice of population studies as well as for obtaining information on the state of homeorhesis in nature for developmental biology [110,111].

Among the prospects for the further development of this direction of research, one can note the improvement of methodology for the morphologic assessment of developmental noise as well as the elaboration of other approaches including genetic, immunological and physiological ones, to assess the mechanisms for ensuring the sustainability of biologic systems [106,112-116]. There is also a great potential to conduct special studies of noise, fluctuations and homeorhesis at different levels, from the gene network to the organism, population and community [117-120].

To realize the opportunities that can be provided through fluctuating asymmetry study, especially with regard to natural populations, obtaining reliable results involves taking into account a number of methodological issues.

First of all, it is necessary to justify the opportunity to reveal the expected effect for the studied object in the sense of its possible reaction to the impact assessed. When collecting samples, it is important to assess the possible influence of the characteristics of population dynamics and the adverse impact of various environmental factors.

At the stage of obtaining primary data, it is necessary to ensure the unambiguity of accounting for the used morphologic characters (including the similarity of the results of repeated measurements and the results of different operators). Another ultimate condition for an applied system of characters is that possible changes in fluctuating asymmetry could appear within the certain backlash allowed by natural selection. It is particularly actual for the characters of the high functional importance exposed to the strict control of natural selection as integrated shape morphometrics elaborated for various morphologic structures. Identification of the "macroeffect" that can be revealed through various statistics is recommended as a target for a population study of developmental stability to provide an opportunity to distinguish the assessed effect among the complex of various impacts that commonly take place in nature.

When interpreting the data obtained, it is important to bear in mind that development stability is not an indicator of hybridization or pollution. When assessing developmental stability, unique information can be obtained on whether certain genetic or environmental changes are accompanied by a change in the state of developing organisms.

Considering the capabilities of the approach, we assess the importance of the estimates of developmental noise. In this regard, an attempt to assess the adaptive significance of each difference in a morphologic trait between the sides of the body is hardly promising. At the same time, changes in the noise level due to a certain effect, which may not be detected by other approaches, are evidence of the initial changes in an organism condition, which may subsequently affect other commonly used indicators of fitness.

The inconsistency of the results of developmental stability study with the data obtained using other approaches (such as assessment of the degree of impact, biodiversity status or genetic variety) provides important information to characterize the peculiarities of the impact and biologic system under study.

Underestimation of the significance of all these factors can lead to the emergence of uncertainties that made it difficult to reliably interpret the results obtained. As practice shows, by taking these moments into account, it is possible to obtain a reliable assessment of the state of the biologic system under study. The estimates turn out to be fairly stable under constant conditions and change under a certain impact. An exhaustive explanation of the revealed pattern and identification of the reason for the presence or absence. An exhaustive explanation of the revealed pattern and identification of the 
reason for the presence or absence of the expected effect is the subject of a special study and is possible if the necessary information is available.

Author Contributions: The review was prepared at all stages, from the beginning to the end, including the reaction to the reviewers comments and suggestions, in collaboration of all three authors V.M.Z., E.G.S., I.E.T. All authors have read and agreed to the published version of the manuscript.

Funding: This work was funded by the government program of basic research in Koltzov Institute of Developmental Biology of the Russian Academy of Sciences in 2020 № 0108-2019-0007.

Acknowledgments: We thank all members of the laboratory of postnatal ontogenesis of the Koltzov Institute of Developmental Biology of the Russian Academy of Sciences for a fruitful cooperation in developmental homeostasis research and anonymous reviewers for the helpful comments and suggestions. The investigations were performed as a part of the state assignment of Institute for biological problems of cryolithozone SB RAS.

Conflicts of Interest: The authors declare no conflict of interest.

\section{References}

1. Mather, K. Genetical control of stability in development. Heredity 1953, 7, 297-336. [CrossRef]

2. Waddington, C.H. The Strategy of the Genes; George Allen \& Unwin: London, UK, 1957; p. 262.

3. Thoday, J.M. Homeostasis in a selection experiment. Heredity 1958, 12, 401-415. [CrossRef]

4. Soule, M.E. Phenetics of Natural Populations. II. Asymmetry and Evolution in a Lizard. Am. Nat. 1967, 101, 141-160. [CrossRef]

5. Zakharov, V.M. Future prospects for population phenogenetics. Sov. Sci. Rev. Sect. F. Physiol. Gen. Biol. Rev. $1989,4,1-80$.

6. Zakharov, V.M.; Graham, J.H. (Eds.) Developmental Stability in Natural Populations; Finnish Zoological Publishing Board: Helsinki, Finland, 1992.

7. Markow, T.A. (Ed.) Developmental Instability: Its Origins and Evolutionary Implications; Kluwer: Dordrecht, The Netherlands, 1994.

8. Moller, A.P.; Swaddle, J.P. Asymmetry, Developmental Stability, and Evolution; Oxford University Press: Oxford, UK, 1997.

9. Polak, M. (Ed.) Developmental Instability: Causes and Consequences; Oxford University Press: New York, NY, USA, 2003.

10. Dongen, S.V. Fluctuating asymmetry and developmental instability in evolutionary biology: Past, present and future. J. Evol. Biol. 2006, 19, 1727-1743. [CrossRef] [PubMed]

11. Graham, J.H.; Raz, S.; Hel-Or, H.; Nevo, E. Fluctuating asymmetry: Methods, theory, and applications. Symmetry 2010, 2, 466-540. [CrossRef]

12. Klingenberg, C.P. Analyzing Fluctuating Asymmetry with Geometric Morphometrics: Concepts, Methods, and Applications. Symmetry 2015, 7, 843-934. [CrossRef]

13. Sinclair, J.P.; Kashian, D.M.; Bradford, J.B.; Freeman, D.C. Variation in Fractal Symmetry of Annual Growth in Aspen as an Indicator of Developmental Stability in Trees. Symmetry 2015, 7, 354-364. [CrossRef]

14. Waddington, C.H. Towards a Theoretical Biology, Prolegomena, International Union of Biological Sciences Symposium; Edinburgh University Press: Edinburgh, Scotland, 1968; Volume 1.

15. Shmalgauzen, I.I. Factors of Evolution (the Theory of Stabilizing Selection), 2nd ed.; Science: Moscow, Russia, 1968.

16. Zotin, A.I.; Alexeeva, T.A. Stability of ontogenesis. In Thermodynamics of Biological Processes; Lamprecht, I., Zotin, A.I., Eds.; Walter de Gruyter: Berlin, Germany; New York, NY, USA, 1985; pp. 485-496.

17. Zakharov, V.M. Population phenogenetics: Analysis of developmental stability in natural populations. Acta Zool. Fenn. 1992, 191, 7-30.

18. Strunnikov, V.A.; Vyshinsky, I.M. Realization Variation in Silkworm. In Problems in Genetics and the Theory of Evolution; Nauka: Novosibirsk, Russia, 1991; pp. 99-114. (In Russian)

19. Zakharov, V.M.; Zhdanova, N.P.; Kirik, E.F.; Shkil, F.N. Ontogenesis and Population: Evaluation of Developmental Stability in Natural Populations. Russ. J. Dev. Biol. 2001, 32, 336-351. [CrossRef]

20. Graham, J.H.; Emlen, J.M.; Freeman, D.C. Nonlinear Dynamics and Developmental Instability. In Developmental Instability: Causes and Consequences; Polak, M., Ed.; Oxford University Press: New York, NY, USA, 2003; pp. 35-50. 
21. Astauroff, B.L. Analyse der erblichen Störungsfälle der bilateralen Symmetrie. Z.Ver-Erbungslehre 1930, 55, 183-262. [CrossRef]

22. Palmer, A.R. Fluctuating Asymmetry Analyses: A Primer. In Developmental Instability: Its Origins and Evolutionary Implications; Markow, T.A., Ed.; Kluwer Academic Publishers: Dordrecht, The Netherlands, 1994; pp. 335-364.

23. Nijhout, H.F.; Davidowitz, G. Developmental Perspectives on Phenotypic Variation, Canalization, and Fluctuating Asymmetry. In Developmental Instability: Causes and Consequences; Polak, M., Ed.; Oxford University Press: New York, NY, USA, 2003; pp. 3-13.

24. Willmore, K.E.; Hallgrímsson, B. Within Individual Variation: Developmental Noise Versus Developmental Stability In Variation; Hallgrímsson, B., Hall, B.K., Eds.; Academic Press: Cambridge, MA, USA, 2005; pp. 191-218.

25. Klingenberg, C.P. Phenotypic Plasticity, Developmental Instability, and Robustness: The Concepts and How They Are Connected. Front. Ecol. Evol. 2019, 7, 1-15. [CrossRef]

26. Lerner, I.M. Genetic Homeostasis; John Wiley \& Sons: New York, NY, USA, 1954.

27. Rasmuson, M. Frequency of morphological deviations as a criterion of a developmental stability. Hereditas 1960, 46, 511-536. [CrossRef]

28. Colborn, T. Clues from wildlife to create an assay for thyroid system disruption. Environ. Health Perspect. 2002, 110, 363-367. [CrossRef]

29. Palmer, A.R.; Strobeck, C. Fluctuating asymmetry: Measurement, Analysis, Patterns. Annu. Rev. Ecol. Syst. 1986, 17, 391-421. [CrossRef]

30. Pertoldi, C.; Kristensen, T.N.; Loeschcke, V. A new method for estimating environmental variability for clonal organisms, and the use of fluctuating asymmetry as an indicator of developmental Instability. J. Theor. Biol. 2001, 210, 407-410. [CrossRef]

31. Freeman, D.C.; Graham, J.H.; Emlen, J.M.; Tracy, M.; Hough, R.A.; Alados, C.L.; Escós, J. Plant developmental instability: New measures, applications, and regulation. In Developmental Instability: Causes and Consequences; Polak, M., Ed.; Oxford University Press: New York, NY, USA, 2003; pp. 367-386.

32. Klingenberg, C.P. A Developmental Perspective on Developmental Instability: Theory. In Developmental Instability: Causes and Consequences; Polak, M., Ed.; Oxford University Press: New York, NY, USA, 2003; pp. $14-34$.

33. Graham, J.H.; Whitesell, M.J.M.F., II; Hel-Or, H.; Nevo, E.; Raz, S. Fluctuating Asymmetry of Plant Leaves: Batch Processing with LAMINA and Continuous Symmetry Measures. Symmetry 2015, 7, 255-268. [CrossRef]

34. Ludwig, W. Das Rechts-Links Problem in Tierreich und Beim Menschen; Springer: Berlin/Heidelberg, Germany, 1932.

35. Van Valen, L. A study of fluctuating asymmetry. Evolution 1962, 16, 125-142. [CrossRef]

36. Neville, A.C. Animal Asymmetry; Amold (Inst.Biol.Stud.Biol.): London, UK, 1976.

37. Palmer, A.R. CHAPTER 16-Antisymmetry. In Variation; Hallgrímsson, B., Hall, B.K., Eds.; Academic Press: Cambridge, MA, USA, 2005. [CrossRef]

38. Lewontin, R.C. The Genetic Basis of Evolutionary Change; Columbia University Press: New York, USA, 1974; Volume 560.

39. McKenzie, J.A.; Clarke, G.M. Diazinon resistance, fluctuating asymmetry and fitness in the Australian Sheep Blowfly, Lucilia cuprina. Genetics 1988, 140, 213-220.

40. Leary, R.F.; Allendorf, F.W. Fluctuating asymmetry as an indicator of stress: Implications for conservation biology. Trends Ecol. Evol. 1989, 4, 214-217. [CrossRef]

41. Erofeeva, E.A.; Yakimov, B.N. Change of Leaf Trait Asymmetry Type in Tilia cordata Mill. and Betula pendula Roth under Air Pollution. Symmetry 2020, 12, 727. [CrossRef]

42. Pertoldi, C.; Kristensen, T.N. A New Fluctuating Asymmetry Index, or the Solution for the Scaling Effect? Symmetry 2015, 7, 327-335. [CrossRef]

43. Hoffmann, A.A.; Woods, R.E. Associating Stress with Developmental Stability: Problems and Patterns. In Developmental Instability: Causes and Consequences; Polak, M., Ed.; Oxford University Press: New York, NY, USA, 2003; pp. 387-401.

44. Palmer, A.R.; Strobeck, C. Fluctuating Asymmetry Analyses Revisited. In Developmental Instability: Causes and Consequences; Polak, M., Ed.; Oxford University Press: New York, NY, USA, 2003; pp. 279-319. 
45. Zakharov, V.M. Linking Developmental Stability and Environmental Stress: A Whole Organism Approach. In Developmental Instability: Causes and Consequences; Polak, M., Ed.; Oxford University Press: New York, NY, USA, 2003; pp. 402-414.

46. Soule, M.E. Allomeric variation. 1. The theory and some consequences. Am. Nat. 1982, 120, 751-764. [CrossRef]

47. Leary, R.F.; Allendorf, F.W.; Knudsen, K.L. Genetic, environmental, and developmental causes of meristic variation in rainbow trout. Acta Zool. Fenn. 1992, 191, 79-95.

48. Zhivotovsky, L.A. A measure of fluctuating asymmetry for a set of characters. Acta Zool. Fenn. 1992, 191, 73-77.

49. Zakharov, V.M.; Pankakoski, E.; Sheftel, B.I.; Peltonen, A.; Hanski, I. Developmental stability and population dynamics in the common shrew, Sorex araneus. Am. Nat. 1991, 138, 797-810. [CrossRef]

50. Zakharov, V.M.; Baranov, A.S.; Borisov, V.I.; Valetskii, A.V.; Kryazheva, N.G.; Chistyakova, E.K.; Chubinishvili, A.T. Health of Environment: Methodology of Assessment; Center for Russian Environmental Policy: Moscow, Russia, 2000.

51. Shadrina, E.G.; Vol'pert, Y.L. Developmental instability of the organism as a result of pessimization of environment under anthropogenic transformation of natural landscapes. Russ. J. Dev. Biol. 2014, 45, 117-126. [CrossRef]

52. Shadrina, E.G.; Vol'pert, Y.L. Experience of applying plant and animal fluctuating asymmetry in assessment of environmental quality in terrestrial ecosystems: Results of 20-year studies of wildlife and anthropogenically transformed territories. Russ. J. Dev. Biol. 2018, 49, 23-35. [CrossRef]

53. Zakharov, V.M.; Shadrina, E.G.; Turmukhametova, N.V.; Ivantsova, E.N.; Shikalova, E.A.; Soldatova, V.Y.; Sharova, N.A.; Trofimov, I.E. Assessment of Plant Status by the Stability of Development in Natural and Anthropogenic Conditions (Fluctuating Asymmetry of Leaf Features of the Silver Birch, Betula pendula Roth). Biol. Bull. 2020, 47, 186-190. [CrossRef]

54. Dobzhansky, T. Genetics of natural populations. XIX. Origin of heterosis through natural selection in populations of Drosophila pseudoobscura. Genetics 1950, 35, 288-302.

55. Thoday, J.M. Components of fitness. Symp. Soc. Exp. Biol. 1953, 7, 96-113.

56. Dobzhansky, T.; Levene, H. Genetics of natural populations. XXIV. Developmental homeostasis in natural populations of Drosophila pseudoobscura. Genetics 1955, 40, 797-808. [PubMed]

57. Adams, M.S.; Niswander, J.D. Developmental 'Noise' and a congenital malformation. Genet. Res. 1967, 10, 313-317. [CrossRef] [PubMed]

58. Bailit, H.L.; Workman, P.L.; Niswander, J.D.; MacLean, C.J. Dental asymmetry as an indicator of genetic and environmental conditions in human populations. Hum. Biol. 1970, 626-638.

59. Parsons, P.A. Fluctuating asymmetry. An epigenetic measure of stress. Biol. Rev. 1990, 65, 131-145. [CrossRef]

60. Shapiro, B.L. Development of human autosomal aneuploid phenotypes (with an emphasis on Down syndrome). Acta Zool. Fenn. 1992, 191, 97-105.

61. Clarke, G.M. The genetic basis of developmental stability. I. Relationships between stability, heterozygosity and genomic coadaptation. Genetica 1993, 89, 15-23. [CrossRef]

62. Leamy, L.J. Dominance, Epistasis, and Fluctuating Asymmetry. In Developmental Instability: Causes and Consequences; Polak, M., Ed.; Oxford University Press: New York, NY, USA, 2003; pp. 142-156.

63. Woolf, C.M.; Markow, T.A. Genetic Models for Developmental Homeostasis: Historical Perspectives. In Developmental Instability: Causes and Consequences; Polak, M., Ed.; Oxford University Press: New York, NY, USA, 2003; pp. 99-115.

64. Strunnikov, V.A.; Strunnikova, L.V. The nature of heterosis, methods of its enhancing and fixation in a series of generations without hybridization. Izv. Akad. Nauk. Seriia Biol. 2000, 6, 679-687. (In Russian)

65. Graham, J.H.; Felley, J.D. Genomic co-adaptation and development stability within introgressed populations of Enneacanthus glorious and E. obesus (Pisces, Centrarchi dae). Evolution 1985, 39, 104-114. [CrossRef]

66. Clarke, G.M.; McKenzie, L.J. Fluctuating asymmetry as a quality control indicator for insect mass rearing processes. J. Econ. Entomol. 1992, 85, 2045-2050. [CrossRef]

67. Parsons, P.A. Fluctuating asymmetry: A biological monitor of environmental and genomic stress. Heredity 1992, 68, 361-364. [CrossRef] [PubMed]

68. Siegel, M.I.; Mooney, M.P.; Taylo, A.B. Dental and skeletal reduction as a consequence of environmental stress. Acta Zool. Fenn. 1992, 191, 145-149. 
69. Zhdanova, N.P. Analysis of Phenotypic Variability under Optimal and Non-Optimal Development Conditions in the Experiment and in Natural Populations Using the Example of a Sand Lizard (Lacerta agilis L.); Koltzov Institute of Developmental Biology of Russian Academy of Sciences: Moscow, Russia, 2003.

70. Valentine, D.W.; Soule, M.E. Effect of p,p'-DDT on Developmental Stability of Pectoral Fin Rays in the Grunion Leureththes tenuis. Nat. Mar. Fish. Bull. 1971, 71, 921-925.

71. Borisov, V.I.; Baranov, A.S.; Valetsky, A.V.; Zakharov, V.M. Developmental stability of the mink Mustela vison under the impact of PCB. Acta Theriol. 1997, 4, 17-26. [CrossRef]

72. Valetsky, A.V.; Dmitrieva, I.L.; Krushinskaya, N.L.; Zakharov, V.M. Social stress impact on developmental stability of laboratory rat Rattus norvegicus. Acta Theriol. 1997, 4, 27-32. [CrossRef]

73. Zakharov, V.M.; Shchepotkin, D.V. Effect of temperature on developmental stability of silkworm (Bombyx mori) strains differing in heterozygosity level. Genetika 1995, 31, 1254-1260. (In Russian)

74. Alekseeva, T.A.; Gubanov, E.A. Energy metabolism at various temperatures in silkworms with different degree of heterozygosity. Izv. AN. Seriya Biol. 1993, 5, 684-693. (In Russian)

75. Strunnikov, V.A. Nature of Heterosis and New Methods of Its Increase; Nauka: Moskva, Russia, 1994. (In Russian)

76. Borisov, V.I.; Valetsky, A.V.; Dmitrieva, I.L.; Krushinscaya, N.L.; Zakharov, V.M. Inbreeding and outbreeding impact on developmental stability of laboratory rat Rattus norvegicus. Acta Theriol. 1997, 4, 67-72. [CrossRef]

77. Jackson, J.F. A search for the population asymmetry parameter. Syst. Zool. 1973, 22, 166-170. [CrossRef]

78. Felley, J. Analysis of morphology and asymmetry in bluegill sunfish (Lepomis macrochirus) in the southeastern United States. Copeia 1980, 1, 18-29. [CrossRef]

79. Lamb, G.D.; Stephenson, D.G. Control of calcium release and the effect of ryanodine in skinned muscle fibres of the toad. J. Physiol. 1990, 423, 519-542. [CrossRef] [PubMed]

80. Chubinishvili, A.T. The status of natural populations of the Rana esculenta-complex in response to anthropogenic influences: A morphogenetic approach. Adv. Amphib. Res. Former Sov. Union 1997, 2, 117-124.

81. Hartl, G.B.; Pucek, Z. Genetic depletion in the European bison (Bison bonasus) and the significance of electrophoretic heterozygosity for conservation. Conserv. Biol. 1994, 8, 67-174. [CrossRef]

82. Baranov, A.S.; Pucek, Z.; Kiseleva, E.G.; Zakharov, V.M. Developmental Stability of Skull Morphology in European Bison Bison bonasus. Acta Theriol. 1997, 4, 79-87.

83. Fowler, K.; Whitlock, M.C. Fluctuating Asymmetry Does Not Increase with Moderate Inbreeding in Drosophila melanogaster. Heredity 1994, 73, 373-376. [CrossRef]

84. Hartl, G.B.; Suchentrunk, F.; Willing, R.; Petznek, R. Allozyme heterozygosity and fluctuating asymmetry in the brown hare (Lepus europaeus): A test of the developmental homeostasis hypothesis. Philos. Trans. R. Soc. Lond. Ser. B Biol. Sci. 1995, 350, 313-323.

85. Zakharov, V.M.; Yablokov, A.V. Skull asymmetry in the Baltic grey seal: Effects of environmental pollution. Ambio 1990, 19, 266-269.

86. Zakharov, V.M.; Trofimov, I.E. Assessment of the Biodiversity Status: Study of Developmental Stability. Biol. Bull. 2020, 47, 115-122. [CrossRef]

87. Pankakoski, E. Epigenetic Asymmetry as an Ecological Indicator in Muskrats. J. Mammal. 1985, 66, 52-57. [CrossRef]

88. Dmitriev, S.G.; Zakharov, V.M. Estimate of cytogenetic homeostasis in natural populations of some small murid rodents. Russ. J. Dev. Biol. 2001, 32, 373-380. [CrossRef]

89. Ims, R.A.; Henden, J.-A.; Killengreen, S.T. Collapsing population cycles. Trends Ecol. Evol. 2008, 23, 79-86. [CrossRef]

90. Zakharov, V.M.; Sheftel, B.I.; Dmitriev, S.G. Climate change and population dynamics: Possible consequences (with particular references to study of small mammals in Central Siberia). Uspekhi Sovrem. Biol. 2011, 131, 435-439.

91. Soule, M.E.; Baker, B. Phenetics of Natural Populations. IV. The Populations asymmetry Parameter in the Butterfly Coenonympha tullia. Heredity 1968, 23, 611-614. [CrossRef] [PubMed]

92. Kat, P.W. The relationship between heterozygosity for enzyme locy and developmental homeostasis in peripheral populations of aquatic bivalves. Am. Nat. 1982, 119, 824-832. [CrossRef]

93. Shaikin, A.V. Developmental stability and phenotypic diversity of color pattern in perch (Perca fluviatilis L.) from different parts of its range. Acta Zool. Fenn. 1992, 191, 151-158. 
94. Zakharov, V.M.; Kryazheva, N.G.; Dmitriev, S.G.; Trofimov, I.E. Evaluation of possible changes in population state due to climate change (with particular references to the study of developmental stability of the European white birch). Biol. Bull. Rev. 2012, 2, 190-193.

95. Shadrina, E.; Vol'pert, Y. Fluctuating Asymmetry of Craniological Features of Small Mammals as a Reflection of Heterogeneity of Natural Populations. Symmetry 2016, 8, 142. [CrossRef]

96. Badyaev, A.V.; Foresman, K.R.; Fernandes, M.V. Rapid environmental change and developmental stability. Vegetation removal causes increased fluctuating asymmetry in a free-living shrew population. Ecology 2000, 81, 336-345.

97. Wojcik, J.M.; Polly, P.D.; Wojcik, A.M.; Sikorski, M.D. Epigenetic variation of the common shrew, Sorex araneus, in different habitats. Russ. J. Theriol. 2007, 6, 43-49. [CrossRef]

98. Zhelev, Z.M.; Tsonev, S.V.; Angelov, M.V. Fluctuating asymmetry in Pelophylax ridibundus meristic morphological traits and their importance in assessing environmental health. Ecol. Indic. 2019, 107, 105589. [CrossRef]

99. Glotov, N.V. Analysis of the genotype-environment interaction in natural populations. Acta Zool. Fenn. 1992, 191, 47-55.

100. Zakharov, V.M.; Pankakoski, E.; Sheftel, B.I. Phenotypic diversity and population dynamics: Another look (with particular references to the common shrew Sorex araneus). Acta Theriol. 1997, 4, 57-66. [CrossRef]

101. Zakharov, V.M.; Demin, D.V.; Baranov, A.V.; Borisov, V.I.; Valetsky, A.V.; Sheftel, B.I. Developmental stability and population dynamics of shrews Sorex in central Siberia. Acta Theriol. 1997, 4, 41-48. [CrossRef]

102. Zakharov, V.M. Appearance, fixation and stabilisation of environmentally induced phenotypic changes as a microevolutionary event. Genetica 1993, 89, 227. [CrossRef]

103. Badyaev, A.V.; Foresman, K.R.; Young, R.L. Evolution of morphological integration: Developmental accommodation of stress-induced variation. Am. Nat. 2005, 166, 382-395. [CrossRef]

104. Pronin, A.V.; Nikolaeva, T.N.; Deyeva, A.V.; Zayatseva, L.G.; Vasil'eva, E.I.; Kirillicheva, G.B.; Baturina, I.G.; Solov'eva, M.S.; Zakharov, V.M. Social stress in laboratory rats Rattus norvegicus results in decreased immune competence of the offspring. Acta Theriol. 1997, 4, 33-40. [CrossRef]

105. Chistyakova, E.K.; Kryazheva, N.G. Possible Application of the Indices of Developmental Stability and Photosynthetic Activity for Studying the States of Natural Plant Populations using the Weeping Birch as an Example. Russ. J. Dev. Biol. 2001, 32, 352-356. [CrossRef]

106. Zakharov, V.M.; Krysanov, E.Y.; Pronin, A.V.; Trofimov, I.E. Study of developmental homeostasis in natural populations. Health of environment concept: Methodology and practice of estimation. Russ. J. Dev. Biol. 2017, 48, 355-368. [CrossRef]

107. Clarke, G.M. Relationships between developmental stability and fitness: Application for conservation biology. Conserv. Biol. 1995, 9, 18-24.

108. Moller, A.P. Developmental stability and fitness: A review. Am. Nat. 1997, 149, 916-932. [CrossRef]

109. Clarke, G.M. Developmental Stability-Fitness Relationships. In Developmental Instability: Causes and Consequences; Polak, M., Ed.; Oxford University Press: New York, NY, USA, 2003; pp. 187-195.

110. Gilbert, S.F. Ecological developmental biology: Developmental biology meets the real world. Russ. J. Dev. Biol. 2004, 35, 346-357. [CrossRef]

111. Zakharov, V.M. Ecological and populational developmental biology: There and back. Russ. J. Dev. Biol. 2004, 35, 358-359. [CrossRef]

112. Alekseeva, T.A.; Zinichev, V.V.; Zotin, A.I. Energy criteria of reliability and stability of development. Acta Zool. Fenn. 1992, 191, 159-165.

113. Ozernyuk, N.D.; Dyomin, V.I.; Prokofyev, E.A.; Androsova, I.M. Energy homeostasis and developmental stability. Acta Zool. Fenn. 1992, 191, 167-175.

114. Parsons, P.A. Environments and evolution: Interactions between stress, resource inadequacy and energetic efficiency. Biol. Rev. 2005, 4, 589-610. [CrossRef]

115. Krysanov, E.Y.; Ordzhonikidze, K.G.; Simanovsky, S.A. Cytogenetic indicators in estimation of environmental state. Russ. J. Dev. Biol. 2018, 49, 36-41. [CrossRef]

116. Pronin, A.V.; Nikolaeva, T.N.; Deeva, A.V. Immunological approach to assessing the health of the environment. Russ. J. Dev. Biol. 2018, 49, 42-47. [CrossRef]

117. Paulsson, J. Summing up the noise in gene networks. Nature 2004, 427, 415-418. [CrossRef] 
118. Simpson, M.L.; Cox, C.D.; Allen, M.S.; McCollum, J.M.; Dar, R.D.; Karig, D.K.; Cooke, J.F. Noise in biological circuits. Wiley Interdiscip. Rev. Nanomed. Nanobiotechnol. 2009, 1, 214-225. [CrossRef]

119. Tsimring, L.S. Noise in biology. Rep. Prog. Phys. 2014, 77, 026601. [CrossRef]

120. Chuang, J.S.; Frentz, Z.; Leibler, S. Homeorhesis and ecological succession quantified in synthetic microbial ecosystems. Proc. Natl. Acad. Sci. USA 2019, 116, 14852-14861. [CrossRef] [PubMed]

(C) 2020 by the authors. Licensee MDPI, Basel, Switzerland. This article is an open access article distributed under the terms and conditions of the Creative Commons Attribution (CC BY) license (http://creativecommons.org/licenses/by/4.0/). 